\title{
A Technical Design Approach to Soil Moisture Content Measurement
}

\author{
${ }^{* 1}$ ATTAH, SU; MADU, N \\ Department of Computer Engineering Michael Okpara University of Agriculture Umudike, Abia state, NIGERIA \\ Corresponding Author Email: sammy.attah16@gmail.com Tel.+2347066102608
}

\begin{abstract}
Soil moisture is an important type of data in many fields; ranging from agriculture to environmental monitoring. Three soil samples were collected at definite proportions to represent the three basic soil types (sandy, loamy and clay soils). The moisture contents of these soil samples were analyzed using the thermogravimetric method. This paper employed the use of PC-based soil moisture content measuring system in order to obtain accurate results. It works with the principle that there is an increase or decrease in soil conductivity as soil moisture increases or decreases respectively. The constructed prototype was used to test the three soil samples as well and the results were compared with that of the thermogravimetric method. The results gotten from this prototype shows the relationship between conductivity and moisture content of the soil. The system was well calibrated in order to get standard readings and conquer the problem of transistor amplification at the signal pick up stage. This therefore makes it possible to get fast an accurate results without wasting much time and energy.
\end{abstract}

DOI: https://dx.doi.org/10.4314/jasem.v22i3.16

Copyright: Copyright $(\odot 2017$ Attah and Madu. This is an open access article distributed under the Creative Commons Attribution License (CCL), which permits unrestricted use, distribution, and reproduction in any medium, provided the original work is properly cited

Dates: Received 15 January 2018; Received: 16 February 2018; Accepted 16 March 2018

Keywords: Soil conductivity, Thermogravimetric, Transistor amplification

As the soil surface evaporates and a crop removes water, the soil has less water than at field capacity, and is now described as having a soil moisture deficit (SMD). However, by measuring the soil moisture content will help monitor its moisture level to keep the soil from being water logged or water stressed. In soil moisture measurement and monitoring, different methods have been used to realize results. These methods are generally grouped into direct and indirect methods. The thermo-gravimetric method involves collecting and weighing soil samples, after which they are dried by heating over an oven until all the water is evaporated. The difference in the weight of the soil sample before and after heating represents the weight of moisture in the soil. It is known as the thermogravimetric method. This method gives a relatively accurate result but is prone to large errors. It is also destructive, labour intensive and time consuming (Campbell et al, 2001). Mathematically the gravimetric soil moisture content gotten from this method can be represented as:

$$
\theta \mathrm{g}=\text { Mwater/Msoil }
$$

Where $\theta_{\mathrm{g}}$ is the gravimetric soil moisture content which is usually represented in percent (Zegelin, 1996), $\mathbf{M}_{\text {water }}$ is the mass of water contained in the voids of the moist soil, and $\mathrm{M}_{\text {soil }}$ is the mass of dry soil.

The indirect methods of measuring soil moisture are categorized according to their means of detecting the variables. These are EM wave, electrical radiological, acoustic and physical based methods. EM wave methods, such as time domain reflectometry (TDR) and frequency domain reflectometry (FDR), measure the EM wave travel time in a waveguide buried in the soil.

The domain reflectometry methods are prone to errors due to attenuation of signals caused by salinity or highly conductive heavy clay soils. EM wave methods that are more elaborate include capturing soil-reflected EM waves transmitted from satellite or an airplane. Other indirect methods such as the neutron scattering method and the gamma ray attenuation method (Zegelin, 1996) involve determining the soil moisture content by making use of high energy from radioactive emissions. Such methods are very expensive, cumbersome and are also sources of potential health hazards (Schmugge et al, 1980). Acoustic methods measure the travel time of a sound wave between a transmitter and a receiver buried in the soil (Adamo et al, 2004). 
The aim of this research is to design and produce a simple, accurate system to measure the level of soil moisture content.

\section{MATERIALS AND METHODS}

For this very work, transistors where used at the pickup circuit. The transistor amplifies base terminal signal at the collector terminal. The amplified signal at the collector terminal is not linear across the output characteristic curve. This fact presents some challenges when using the transistor as an amplification device in the signal pick-up stage.

Block Diagram: The block diagram below shows the basic components of the system.

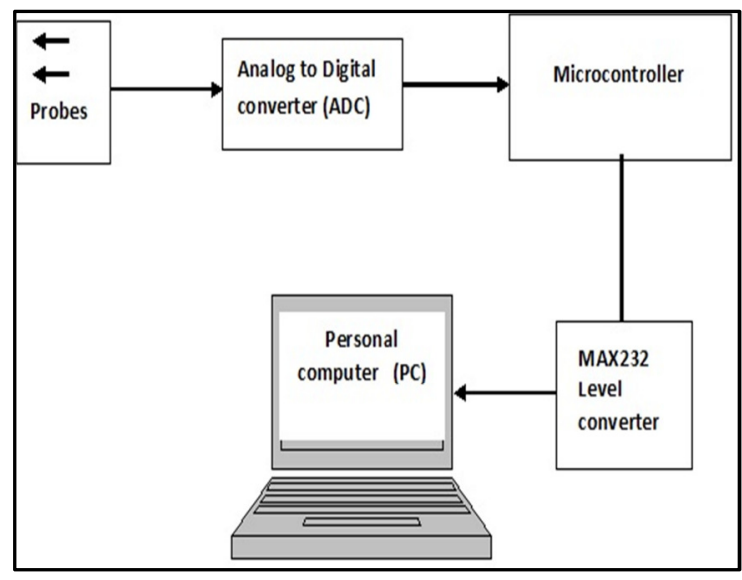

Fig. 1: Block Diagram of a PC based Soil moisture content measuring system

As shown in the figure above, the system makes use of probes as the basic input device. Probes are portable objects that are used as sensors in getting analog signals from a desired specimen. The probe used in this work is a pair of copper probes which work with the principle that the resistivity or conductivity of a soil sample decreases or increases with respect to its dampness.

This is true because water contains ions that are capable of carrying electrical charges. The use of probes makes this technique of soil moisture measurement extremely sensitive to small changes in soil moisture content particularly at dry soil moisture content (Zegelin, 1996). They are inserted directly in the soil to get analog input continuously. We say that if we have a given soil sample $\mathrm{W}$ with a certain level of dampness $\mathbf{d}_{w}$, the conductivity of the soil sample $\boldsymbol{\sigma}_{w}$ is directly proportional to its dampness $\mathbf{d}_{w}$.

Mathematically we can represent this as:

$$
\sigma w \alpha \mathrm{d} w
$$

The analog signals gotten by the probes serve as the input to the system and are further processed by resistors, capacitor and transistor which serve to enhance the quality of the signal input. The resulting amplified signal is sent to the analog to digital converter (ADC). The ADC sits at the boundary between the analog and the digital part of the system. It converts continuous analog input signals to digital signals. The digital output will be a two's complement binary number that is proportional to the input. It is interfaced with the emitter and collector legs of the amplifying transistor as shown in the circuit diagram in figure 2 .

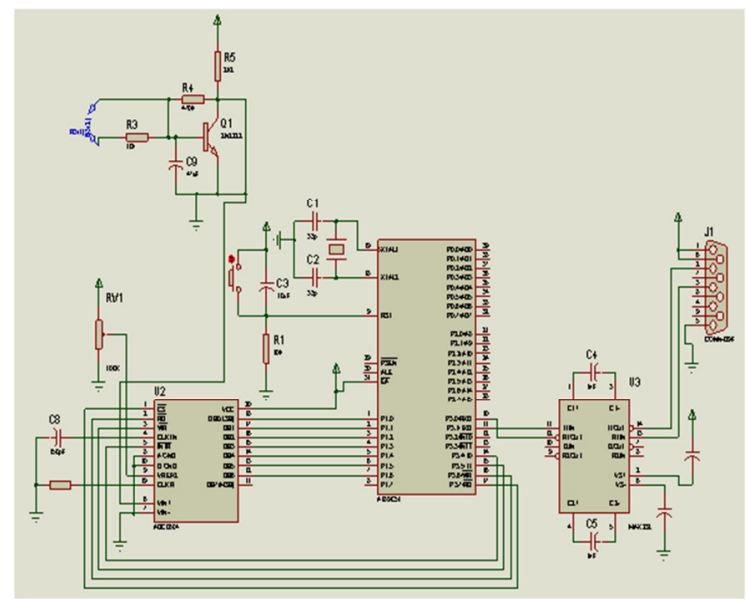

Fig 2. Circuit schematic diagram

The ADC is also interfaced with the microcontroller as such the digital signals from the ADC are sent to the AT89C51. AT89C51 is a low-power; highperformance CMOS 8-bit microcomputer with $8 \mathrm{~K}$ bytes of flash programmable and erasable read only memory (PEROM) (Atmel corporation, 2000) thus making it suitable for the nature of this work. It functions to process and store the digital signals further.

Assembly language was used to program the microcontroller in order to gain more control for the desired process. The output of the microcontroller is fed into MAX 232 which is an integrated circuit chip that has the function of converting TTL voltage levels to RS232 level and vice versa. The PC uses a DB 9 port to connect to the rest of the system. It serves as the unit that displays the results gotten from our measurement. The software program used by the PC in this work is visual basic 6.0 and is suitable because of its graphical interface. The visual basic interface was designed to have a start button, a stop button, a continue button and an exit button. 
The flow chart below further gives a clear description of how the system works.

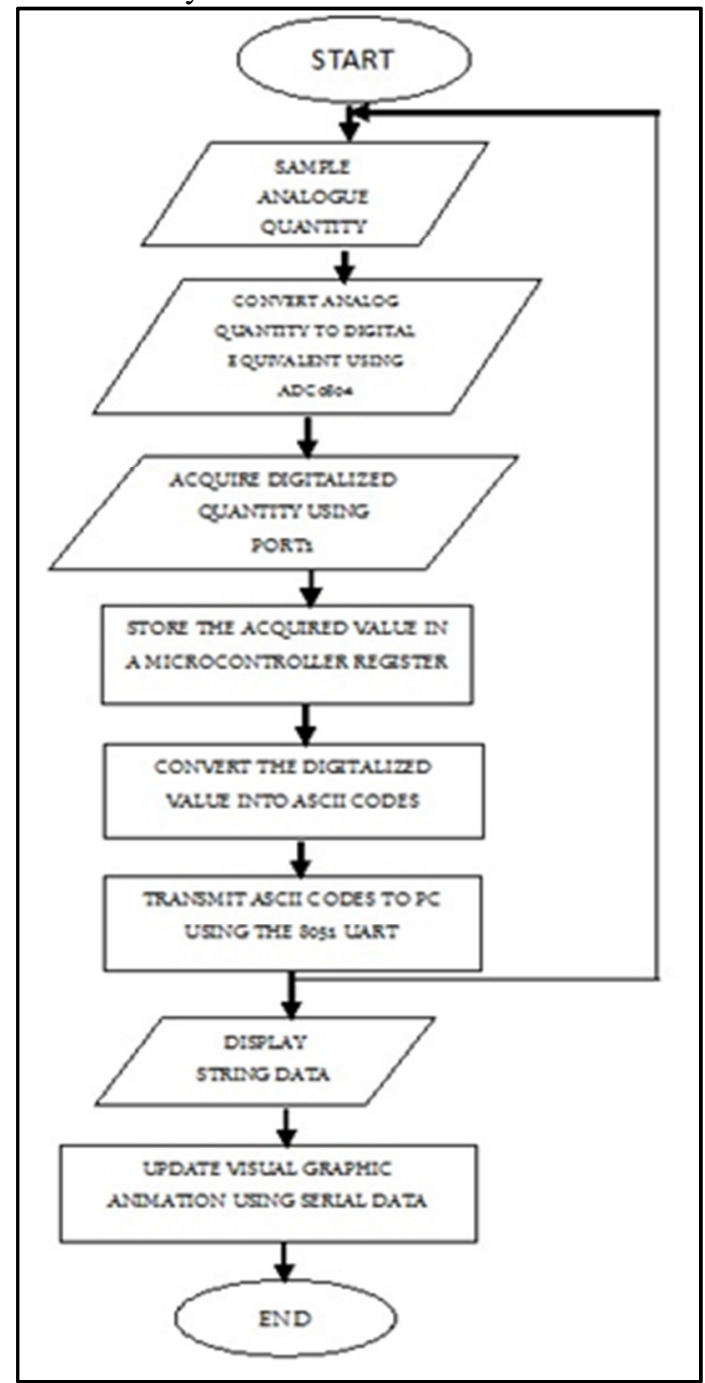

Fig 3. System Flow Chart

Testing and system analysis: The components are tested one after the other with logic probe of the multimeter. The components were first mounted on the bread board so as to check for malfunctioning. It initially malfunctioned due to wrong placing of their polarities. The errors were pointed out, corrected and then transferred to the Vero board for permanent connection. Assembly language program was then burnt into the microcontroller in order to perform code conversions and also to store codes in its registers. The D-type 9 pin RS 232 cable was also tested to ensure that it functions properly and was interfaced with the computer. A visual basic program was written in a bid to help display the results gotten from measuring various soil samples. The entire system was then packaged.
To test the functionality of this system, the thermogravimetric experiment was carried out and its readings compared with that of the system. To do this three wet soil samples were collected to represent the three basic soil types (i.e. sandy, loamy and clay soil). There masses were weighed and initial readings were taken. The sample was heated in an oven and brought out at intervals to be weighed and the measuring system was used to measure conductivity; the results were recorded.

\section{RESULTS AND DISCUSSION}

- Clay soil: The Initial mass of the wet clay soil was 194.92 grams and the final mass of the dry clay soil after heating was stable at 166.60 grams. Therefore, the initial percentage moisture content is $17 \%$ and the system gave an initial reading of 28 as well.

Table 1 Results from measuring the moisture content of clay soil

\begin{tabular}{llll}
\hline $\begin{array}{l}\text { Time } \\
\text { Interval } \\
\text { (hours) }\end{array}$ & $\begin{array}{l}\text { Mass } \\
\text { (grams) }\end{array}$ & $\begin{array}{l}\% \\
\text { moisture } \\
\text { content }\end{array}$ & $\begin{array}{l}\text { Measuring } \\
\text { system }\end{array}$ \\
\hline $1: 30$ & 190.01 & 14.1 & 28 \\
$2: 30$ & 185.08 & 11.1 & 27.02 \\
$3: 30$ & 179.70 & 7.9 & 21.7 \\
$4: 30$ & 175.96 & 5.6 & 16.4 \\
$5: 30$ & 171.64 & 3 & 11 \\
$6: 30$ & 166.64 & 0.02 & 5.5 \\
$7: 30$ & 166.60 & 0 & 5 \\
\hline
\end{tabular}

From the above table, we can plot a graph of conductivity gotten from the PC based system against the percentage moisture content.

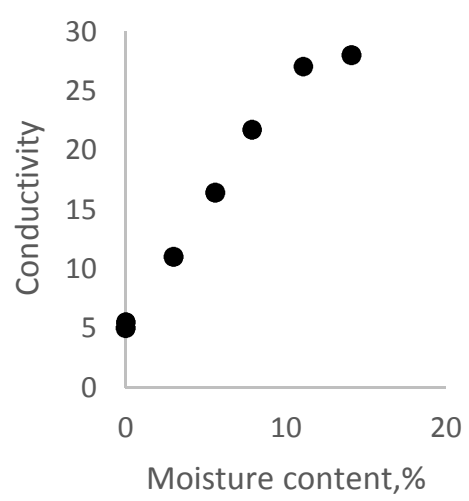

Fig.4: A plot of conductivity against moisture content for clay soil From the above plot, in clay soil conductivity increases as the moisture content increases as well. This further gives prove to equation II. At the point where the curve becomes flat, the soil has reached its peak level of conductivity and as such there are little or no changes in the readings of the system therefore we can say that the soil has attained saturation. Clay soil has high conductivity, thus it takes a longer time for it to achieve saturation. 
- Loamy soil: The initial mass of the wet loamy soil was 177.15 grams and the final mass of the dry loamy soil was 146.58 .

Table 2 Results from measuring the moisture content of loamy soil

\begin{tabular}{lllll}
\hline $\begin{array}{l}\text { Time } \\
\text { Interval } \\
\text { (hours) }\end{array}$ & $\begin{array}{l}\text { Mass } \\
\text { (grams) }\end{array}$ & $\begin{array}{l}\% \\
\text { moisture } \\
\text { content }\end{array}$ & $\begin{array}{l}\text { Measuring } \\
\text { system }\end{array}$ & \\
\hline $1: 30$ & 171.89 & 17.3 & 14.02 & \\
$2: 30$ & 166.49 & 13.6 & 14.00 & \\
$3: 30$ & 161.37 & 10.1 & 13.81 & \\
$4: 30$ & 156.73 & 7 & 12.25 & \\
$5: 30$ & 151.43 & 3.2 & 8.02 & \\
$6: 30$ & 148.05 & 1 & 4.21 & \\
$7: 30$ & 146.58 & 0 & 4.00 & \\
\hline$W e$ & plot a & graph of & conductivity against the
\end{tabular}
percentage moisture content for loamy soil.

Conductivity

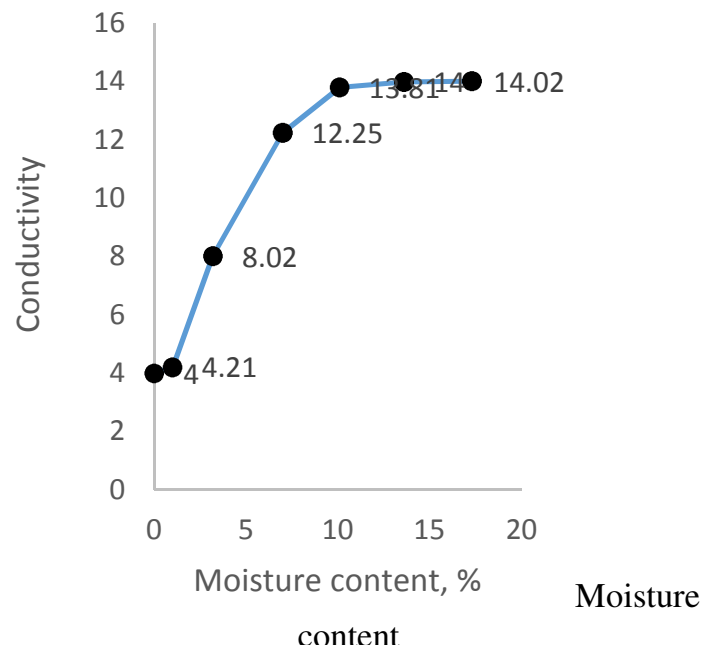

Fig.5: A plot of conductivity against moisture content for loamy soil

From the plot above, there is a visible linear increase in the conductivity of loam soil as the dampness of the soil increases. This increase continues until it attains saturation. At this point there are no visible changes in our calibrated system. Loamy soil tends to achieve saturation much faster.

Sandy soil: The initial mass of the wet sandy soil was 197.94grams and its mass after drying was 169.75 grams.

Table 3 Results from measuring the moisture content of sandy soil

\begin{tabular}{llll}
\hline $\begin{array}{l}\text { Time } \\
\text { Interval } \\
\text { (hours) }\end{array}$ & $\begin{array}{l}\text { Mass } \\
\text { (grams) }\end{array}$ & $\begin{array}{l}\% \\
\text { moisture } \\
\text { content }\end{array}$ & $\begin{array}{l}\text { Measuring } \\
\text { system }\end{array}$ \\
\hline $1: 30$ & 194.42 & 14.5 & 15.01 \\
$2: 30$ & 189.57 & 11.7 & 14.98 \\
$3: 30$ & 184.35 & 8.6 & 12.23 \\
$4: 30$ & 179.32 & 5.6 & 9.85 \\
$5: 30$ & 174.48 & 2.8 & 7.62 \\
$6: 30$ & 170.59 & 0.5 & 5.34 \\
$7: 30$ & 169.75 & 0 & 5.00 \\
\hline
\end{tabular}

From the above table, we can plot a graph of conductivity gotten from the PC based system against the percentage moisture content.

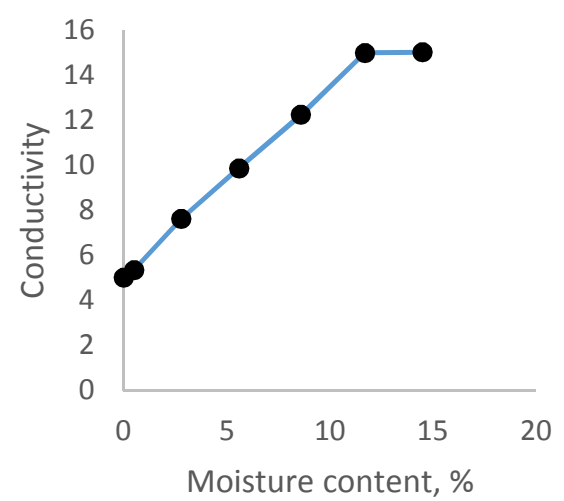

Fig. 6: A plot of conductivity against moisture content for sandy soil

From the plot of the values of conductivity against moisture content for sandy soil, we also observe similar characteristics as in that of clay and loamy soils that is an increase in soil conductivity values as soil dampness increases as well.

System Evaluation: There are possible factors that can serve to make readings differ considerably in measurement in this case they are: 1.Voltage supply and 2.Specific resistor values used in the circuit.

The issue of voltage supply was taken care of by using a 9volts zener diode across the signal pick-up circuit.

Next, other necessary adjustments were carried out to overcome the problem of difference in circuit amplification factor due to differing resistor value. It was solved using software approach to create a standard method of calibration by carrying out the following processes.

Having two measuring systems A and B with amplification factors of 20 and 25 respectively, A has an initial reading of 40 and $B$ has an initial reading of 50 and they are used to get readings from the same soil sample, system A gets a reading of 100 and B gets a reading of 125 , to get a standard for both systems, we do the following.

$$
\frac{\text { System reading }- \text { intial reading }}{\text { Amplification factor }}
$$

Therefore for system A we will have $\frac{100-40}{20}=3$

For system B we have $\frac{125-50}{25}=3$ 
This issue of amplification factor disparity was conquered in our modeled system by implementing the calculations above in the software used for this work.

Conclusion: This work clearly shows the relationship between conductivity and the moisture content of the soil. From the results obtained, we notice an increase or decrease in conductivity as soil moisture increases or decreases. The model developed was one that conquers the problem of amplification factor due to transistors at the signal pickup stage. It provides an easier and more effective means of getting accurate data when compared to other methods of moisture content measurement. The system is very beneficial in the areas of agriculture and environmental control.

\section{REFERENCES}

Adamo, F et al (2004). An Acoustic Method for Soil Moisture Measurement. IEEE transactions On Instrumentation and Measurement, Vol.53.

Atmel Corporation (2000). 8-bit microcontroller with $4 \mathrm{~K}$ Bytes flash.

Campbell, DJ; Henshall, JK (2001). Bulk density. In: K.A. Smith and C.E. Mullins, Soil and Environmental Analysis: Physical Methods. Marcel Dekker, New York, pp. 315-348.

Gee, GW; Dodson, ME (1981). Soil Water Content by Microwave Drying: A routine Procedure. Soil Sci. Soc. America. J. 45: 1234-1237

Jones, LA; Kimball, JS; Podest, E; McDonald, KC; Chan, SK; Njoku, EG (2009). A Method for Deriving Land Surface Moisture, Vegetation, and Open Water Fraction from AMSRE. Proc. IEEE Int. Geosci. Rem. Sens. Symp. (IGARRS'09), July 13-17, Cape Town, South Africa. DOI:10.1109/IGARSS.2009.5417921
Muhammad et al (2005). The 8051 microcontroller and embedded systems $5^{\text {th }}$ edition, Prentice Hall INC.

Mullins, CE (2001). Matric potential. In: K.A. Smith, and C.E. Mullins, Soil and Environmental Analysis: Physical Methods. Marcel Dekker, New York, pp. 65-93.

Organization, WM (2010). WMO GuideMeasurement of Soil moisture, 2010 WMO: Switzerland.

Piuzzi E et al. (2010). An improved reflectometric method for soil moisture measurement exploiting an innovative triple-short calibration. IEEE transactions on Instrumentation and Measurement 59.

Schmugge et al (1980). The utility of surface temperature measurements for the remote sensing of Sun for soil water status. $J$. Geophysical Res. 80: 3044-3049.

Skye instruments limited (2012). Water and soil. Soil measurement notes 4-6.

Zegelin (1996). Retrieval of soil moisture and vegetation characteristics by use of ERS-1 wind Scatterometer over arid and semi-arid areas. $J$. Hydrology 188-189, 361-384. 